\title{
The Impact of Leadership Style on Performance of Nurses
}

\author{
Sutikno M. ofar
}

\begin{abstract}
This study aims to find the impact of leadership style (Transformational leadership and Transactional leadership) on the performance of Nurses in the Health sector. The study conducted in Temar medical Center, Erbil, Kurdistan Region. Fifty questionnaires have been distributed. The data collected analyzed by Statistical Package for the Social Sciences (SPSS). After ensuring the reliability and validity, the results indicated both leadership style, Transformational leadership, and Transactional leadership had a positive and significant impact on nurses' performance. However, the results showed Transformational leadership style more important compared to Transactional leadership on Nurse's performance.
\end{abstract}

\section{Introduction}

An examination of the literature in the fields of leadership styles finds that the area has been independently linked to job performance. For example, researchers have examined the links between leadership styles and performance (Bycio et al., 1995; Howell \& Avolio, 1993). A few studies have been conducted on the effect of these factors in the health sector. However, this study discusses these factors simultaneously. This research study is an attempt to fill gaps in the literature. Additionally, limited studies have utilized leadership styles for managers within the same research study in relation to nurses performance or Therefore, this study may be a stepping stone to further enhance the field of leadership styles in health sector. 
Unlike the early leadership theories that focus on effective and successful leader characteristics such as traits, behaviour and contingency, transformational leadership has shifted emphasis from the traditional or transactional model toward the study of transformational leadership. Transformational leadership occurs when a leader raises the level of awareness about the value of desired results and expands subordinates' wants and needs (Bass, 1985). According to Bass 1985, transformational leaders allow subordinates to think creatively, analyze problems from different angles and provide better solutions by using technology. Pounder (2008) claimed that organizations can reduce job stress and burnout by adopting a transformational leadership style. Many studies have signified that transformational leadership has positive effects on followers' efforts and satisfaction (Pounder, 2008).

Job performance is one of the most notable indicators in evaluating organizational performance. Schermerhorn (1975) described job performance as quality and quantity achieved by individuals or groups upon fulfilling a task. Munchinsky (2014) proposed that job performance is a set of employee behaviors that can be measured, monitored and evaluated in terms of achievement at the individual level. According to Schermerhorn (1975), job performance is the result of quality and quantity once employees complete a mission. Due to its importance, several studies have been conducted to explore ways of enhancing employee performance (Kahya, 2009). Nurses' performance can be described as the duties performed by nurses. Acording to Kahya (2009), the effective management of individual performance is essential to the implementation of organizational strategies. 


\section{Chapter One}

\section{Research Methodology}

\subsection{Research Problem}

Head nurses play an important role in the health sector, and the head nurses' leadership style has a significant effect on the nurse's work outcomes. Temar medical Center, Kurdistan Region. The turnover rate is very high, and they are concerned about the head nurse's way of dealing with them. This increasing turnover rate becomes the reason for several issues like shortage of nurses, workload, cost of hiring, etc. Thus this study aims to investigate the effective leadership style of the head nurses so that the hospital can overcome the issue of the nurse's turnover as the study mentions that head nurses can play a key role to retain the key employees in an institute.

\subsection{Research Objectives}

1. To find the impact of Transformational on Nurses performance.

2. To find the impact of Transactional on Nurses performance.

3. To provide the recommendations which might be useful to the health sector

\subsection{Research Importance}


The study will be of immense benefit to the staff of Temar medical Center, how the concept of Job satisfaction and job performance are valued and understood and the need for all to pay attention to a variety of motivation issues or financial incentives for staff.

\subsection{Research Hypotheses}

H1: Transformational leadership has positive and significant impact on Nurses performance.

H2: Transactional leadership has positive and significant impact on Nurses performance.

\subsection{Research Model}

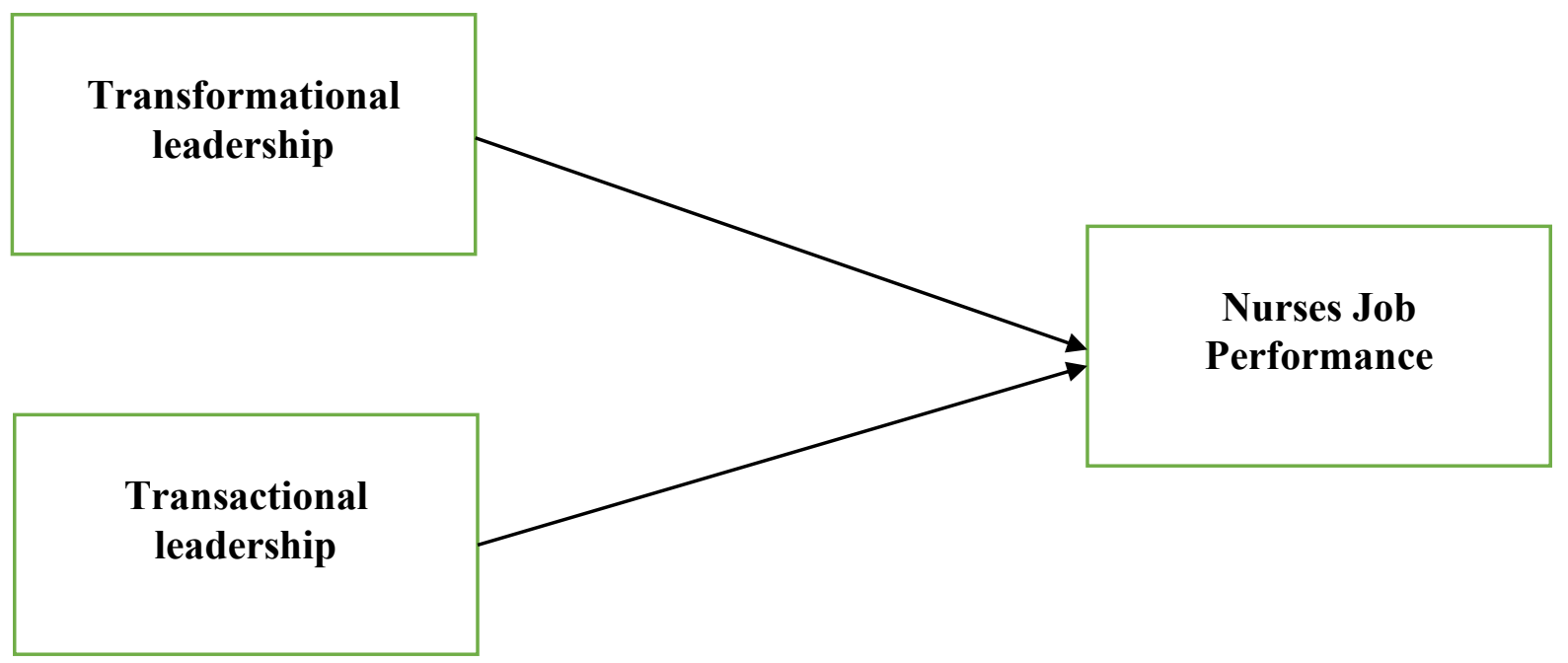

Figure1 Framework

\subsection{Population and Sample}

The Target population of the current study is the nurses at Temar medical Center in Erbil, Kurdistan Region, Iraq. the sample size is 50 Nurses.

\subsection{Data Collection Tool.}


The Data were collected via the Questionnaire, and the Questionnaire has been written in two languages English and Kurdish and all the question is simple to understand. Besides, the researchers were randomly distributed 50 Questionnaires among the nurses at Temar medical Center.

\subsection{Statistical Analysis Tools}

The collected Data analysed by Statistical Package for the Social Sciences (SPSS) to find the Validity, Reliability, correlation and regression of current model.

\section{Chapter Two}

\section{Literatures Review}

\subsection{Leadership}

Leadership The constant changes in organizational life highlight the increasing importance of leadership. As such, leadership is one of the most studied topics worldwide (Kuchler, 2008). Leadership can be described as an interaction process between leaders and their employees, whereby leaders attempt to influence employees to fulfill common goals (Northouse et al. 2010). Leadership style is the manner and approach of motivating people, providing direction and achieving goals (Amirul \& Daud, 2012). Style can either encourage or discourage empolyees, which can in turn lead to increasing or decreasing performance levels (Kuchler, 2008). However, leadership has been of interest to many researchers, who have proposed numerous leadership theories and models. According Amirul and Daud (2012), leadership theories can be divided into four categories: trait, behavioral, contingency, and the transformational and transactional theories. Unlike the early leadership theories that focus on effective and successful leader characteristics such as traits, behaviour and contingency, transformational leadership has shifted emphasis from the traditional or transactional model toward the study of transformational leadership.

2.1.1 Transformational leadership occurs when a leader raises the level of awareness about the value of desired results and expands subordinates' wants and needs (Bass, 1985). According to Bass (1985), transformational leaders allow subordinates to think creatively, analyse problems 
from different angles and provide better solutions by using technology. Gill et al. (2006) claimed that organizations can reduce job stress and burnout by adopting a transformational leadership style. Many studies have signified that transformational leadership has positive effects on followers' efforts and satisfaction (Pounder, 2008). Compared with other styles, transformational leadership is deemed advantageous in developing leaders and enhancing subordinates' loyalty, trust and self-esteem (Northouse, 2012). Therefore, transformational leadership is the most effective form of leadership, where the leaders are closely engaged with, and motivate their subordinates to achieve beyond their transactional agreements Bass (1985). According to Northouse, (2012), there are several leadership styles, including autocratic, bureaucratic, laissezfaire, democratic, participative, situational, transactional and transformational. However, if leaders wish to produce positive effects on employees and organizations, then leadership should be shifted from the traditional autocratic style to more sociable styles (Bass. 2003). Effective leaders adopt styles that support employees, provide them with a vision, instill hope and motivate them to think innovatively. All these features are observed in transformational leadership. Moreover, the transformational style functions better than other styles in terms of employees retaining their jobs besides having job satisfaction (Berggren \& Severinsson, 2003). This type of leadership is more motivational in contrast with other styles (Kirkman et al., 2009). In the current study, transformational leadership will be discussed.

2.1.2 Transactional leadership. The notion of transactional leadership grew out of the exchangebased theories of leadership that dominated the leadership literature until the 1980's. Bass (1985) defined transactional leaders as leaders who identify the needs of their followers and engage in exchange relationships with them based on objectives to be met. The higher order factor of transactional leadership includes: contingent reward, active management by exception, and passive management by exception. Contingent reward leadership is characterized by the exchange of rewards from leaders to followers for accomplishing objectives (Bass \& Avolio, 1993). With this style of leadership, the leader sets clear goals and objectives and clearly specifies what rewards (financial or nonfinancial) can be expected for achieving goals. Both active and passive management by exception are characterized by the use of discipline to correct undesired behavior from followers. The difference between the two approaches becomes apparent when one considers the monitoring pattern of the leader. Active management by exception is characterized by the leader's continued observation of followers to ensure that agreed upon standards of performance 
are met (Antonakis et al., 2003). In contrast, passive management by exception leaders only intervene when mistakes have already occurred (Antonakis et al., 2003)

\subsection{Job Performance}

Nurses are one of the inputs to any healthcare system and have strong effect on the organization performance (Fritzen, 2007). Health tourism hospital with nurses as majority workforce should take cognizance of the importance of their job performance which is the fundamental value of achieving high standard of patient care. In addition, how effective nurses perform their duties is associated with the direct care of their patients (Karem, Mahmood, Jameel and Ahmad, 2019). Hence, hospital management should extend their view exceeding the medical perspective and apply a holistic social approach to improve their nurses' job performance. In the healthcare context, nurses' job performance focuses on understanding patients' needs by delivering proper care and solutions. It is imperative that nurses should be able to adjust their performance in order to reflect patients' reality (Karem et al, 2019). Since nurse-patient interface embraces element of the nursepatient interaction to co-produce a service, the aspect of interaction is important to meet the incremental patients' expectation. The expressive and interactive performance of nurses will be mostly evaluated because patients are more sensitive towards the service behavior the nurses (Karem et al, 2019). On top of that, it was emphasized that caring processes have to be accommodated into the performance criteria to fulfill patient needs in terms of intimate and complex service means (Jameel and Ahmad,2020). The aspect of caring processes has a primary influence in formulating expectations and controlling patient experiences. On the other hand, it was stated that to ensure an excellent delivery of healthcare that involved interaction between patient and caregiver is difficult as it is related to human behavior (Jun et al., 1998). However, the performance of nurses is still depending on this aspect as patient's evaluation usually refers to their sentimental reaction to prominent aspect of the context and outcome of their experience (Pascoe, 1983). Patient's experience may be ultimately used to verify the medical treatment provided whether it has met their expectations (Babakus and Mangold, 1992) This study focuses on the job performance of nurses because successful healthcare organization generally customizes the experience of healthcare around the individual needs of its patients and the needs of its staff members (Kerfoot, 2000). It is widely accepted that excellent nurses' performance is more likely to generate satisfied patients and create more favorable outcomes to the organization. Conversely, if the nurses' performance declines, it will lead to unwanted consequences such as substandard of patient care and growing number of patient complaints. In a nutshell, hospital with better nurses' 
performance has the competitive advantage over those that do not perceive job performance as an important factor for the patients to return to the same hospital (Bruce et al., 1998).

Job performance is one of the most notable indicators in evaluating organizational performance (Wall et al., 2004). Schermerhorn (1989) described job performance as quality and quantity achieved by individuals or groups upon fulfilling a task. Munchinsky (2003) proposed that job performance is a set of employee behaviors that can be measured, monitored and evaluated in terms of achievement at the individual level. According to Schermerhorn (1989), job performance is the result of quality and quantity once employees complete a mission. Due to its importance, several studies have been conducted to explore ways of enhancing employee performance (Kahya, 2009). Nurses' performance can be described as the duties performed by nurses. According to Amos et al. (2004), the effective management of individual performance is essential to the implementation of organizational strategies.

Some researchers (Smith \& Peterson, 1988) believe that there are certain characteristics leaders must have in order to create employee job satisfaction and commitment: (a) Empowerment and (b) clear vision. In order for transformational leaders to be effective, their followers must share their vision for the organization and be willing to put the goals of the organization before their own personal goals and objectives (Hater \& Bass). Other researchers (Bass, Avolio, \& Goodheim, 1987; Bass, Waldman, Avolio, \& Bebb, 1987) found that employee satisfaction is positively related to transformational leadership style. In further support of transformation leadership, some researchers (Bass, 1985; Bycio, Hackett, \& Allen, 1995; Hater \& Bass, 1988; Howell \& Avolio, 1993; Shamir, Zakay, Breinin, \& Popper, 1998; Yammarino \& Bass, 1990) found that leaders who have transformational leadership characteristics have been known to motivate followers to exert effort to achieve organizational goals. 


\section{Chapter Three}

\section{Empirical Study}

This chapter deals with the empirical analysis, it consist of the questions of survey and its respondents in addition to analyzing the data and interpretation of result.

\subsection{Data Collection tool and research instrument}

As we have mentioned in chapter one the data collected by questionnaires. With questionnaire we asked responder to answer on the first section the questions related to demographic (age, gender and work experience. while the second section consists form the questions of each variables Achievement 4 Items. Salary 4 Items , Culture items and Working environment 5 Items, Job satisfaction 5 items. However, all the questions adopted from prior studies

\subsection{Data Analysis}

After collecting the required data, the next step will be the analysis of the collected data. Data analysis includes analyzing and categorizing the collected data. In this research the collected data from the questionnaire has been quantitatively analyzed to support the hypotheses. 


\subsubsection{Gender frequency}

Table 1 Gender

\begin{tabular}{|c|c|c|}
\hline Variable & Number & Percent \\
\hline Male & 8 & $27 \%$ \\
\hline Female & 42 & $73 \%$ \\
\hline Total & 50 & $100 \%$ \\
\hline
\end{tabular}

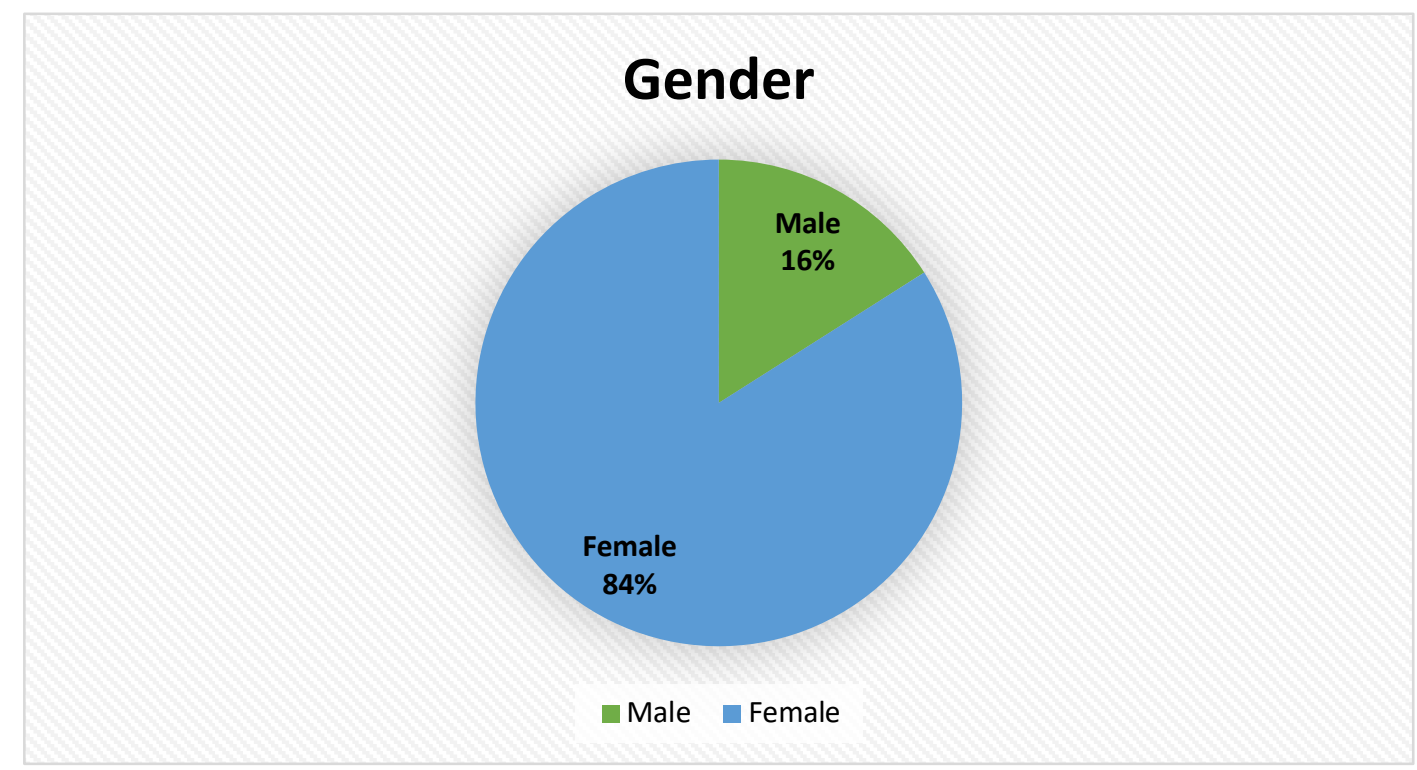

Figure 2 Gender

Base on figure 2 and Table 1 the majority of responded Female $84 \%$ and Male $16 \%$. 


\subsubsection{Years of work experience frequency}

Table 2 Work Experience

\begin{tabular}{|c|c|c|}
\hline$<7$ years & 29 & $60 \%$ \\
\hline $7-12$ years & 12 & $23 \%$ \\
\hline $13-18$ Years & 6 & $10 \%$ \\
\hline$>18$ Years & 3 & $7 \%$ \\
\hline Total & $\mathbf{5 0}$ & $\mathbf{1 0 0 \%}$ \\
\hline
\end{tabular}

\section{Work Experience}

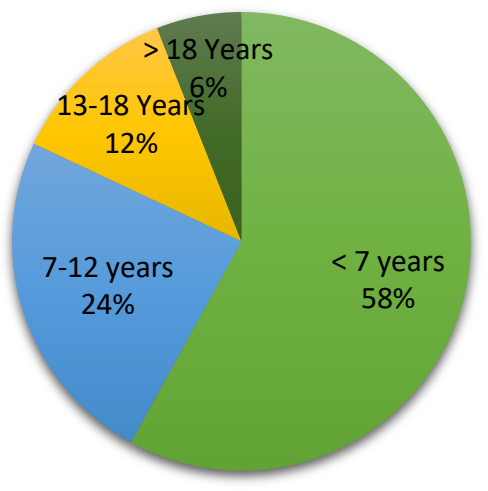

$$
\square>7 \text { years } \quad 7-12 \text { years } \square 13-18 \text { Years } \square>18 \text { Years }
$$

Figure 3 work Experience 
Based on Table 2 and Figure 3 most of nurses working experience less than 7 years with 58\% followed by $24 \%$ working experience between 7 to 12 years then only $12 \%$ between 13 to 18 years working experience and lastly, $6 \%$ had working experience more than 18 Years.

\subsubsection{Level of Education}

Table 3 Level of education

\begin{tabular}{|c|c|c|}
\hline Diploma & 27 & $54 \%$ \\
\hline Bachelor & 21 & $42 \%$ \\
\hline Master and above & 2 & $4 \%$ \\
\hline Total & 50 & $100 \%$ \\
\hline
\end{tabular}

\section{Level of education}

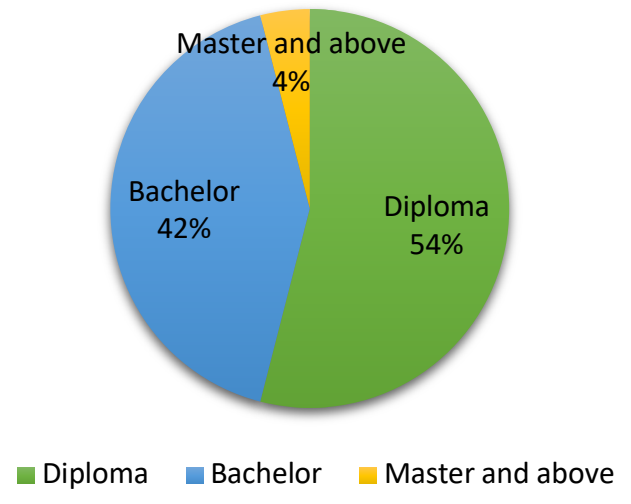

Figure 4 Level of Education

Based on Table 3 and figure 4 most of nurses holdiong Diploma 54\% followed by Bachelor degree $42 \%$ and only $4 \%$ holdong Master and above. 


\subsection{Results}

\subsubsection{Reliability and Validity}

The reliability of this study has achieved (see table 4) due to all the results met the requirement and criteria. the level of reliability for all the items exceed 0.70 which is considered good internal consistency and over considered Excellent internal consistency (Sekaran \& Bougie, 2010).

The validity also has been examined by factor loading and all the items loadings higher than 0.7 the recommended level by (Hair, Sarstedt, Hopkins, \& Kuppelwieser, 2014) the validity has been achieved too.

Table 4 Reliability and Validity

\begin{tabular}{|c|c|c|c|}
\hline Variables & items & $\begin{array}{l}\text { Factor } \\
\text { loading }\end{array}$ & $\begin{array}{l}\text { Cronbach } \\
\text { alpha }\end{array}$ \\
\hline Transformational & TRL1 & .832 & \\
Leadership & TRL 2 & .854 & .722 \\
& TRL 3 & .878 & \\
& TRL 4 & .730 & \\
\hline & TFL1 & .954 & \\
Transactional & TFL 2 & .881 & .744 \\
Leadership & TFL 3 & .824 & \\
& TFL 4 & .845 & \\
\hline & JS1 & .834 & \\
Job Performance & JS2 & .856 & \\
& JS3 & .784 & 7.90 \\
& JS4 & 712 & \\
& JS5 & .776 & \\
\hline
\end{tabular}




\subsubsection{Correlation}

Pearson correlation conducted to measure and understand the relationship between independent variable (IV) and Dependent variable (DV) in this study. (Cohen, 1988) interpret the range of correlation $0.1-0.29$ Weak relationship, $0.3-0.49$ Moderate relationship and $0.5-1.00$ Strong relationship. Table 4 Depicted the results of correlations and all the results showed moderate and Strong relationship see Table 5.

Table 5 Pearson correlation

\begin{tabular}{|c|c|c|c|c|}
\hline \multicolumn{2}{|c|}{} & TRL & TFL & JP \\
\hline \multirow{4}{*}{ TRL } & Pearson Correlation & 1 & $.410^{*}$ & $.537^{* *}$ \\
\cline { 2 - 5 } & Sig. (2-tailed) & & .000 & .000 \\
\cline { 2 - 5 } & $\mathrm{N}$ & 50 & 50 & 50 \\
\hline \multirow{4}{*}{ TFL } & Pearson Correlation & $.310^{*}$ & 1 & $.503^{* *}$ \\
\cline { 2 - 5 } & Sig. (2-tailed) & $0.410^{*}$ & & .000 \\
\cline { 2 - 5 } & $\mathrm{N}$ & 50 & 50 & 50 \\
\hline \multirow{3}{*}{ JP } & Pearson Correlation & $.567^{* *}$ & $.503^{* *}$ & 1 \\
\cline { 2 - 5 } & Sig. (2-tailed) & .000 & .000 & \\
\cline { 2 - 5 } & $\mathrm{N}$ & 50 & 50 & 50 \\
\hline
\end{tabular}

**. Correlation is significant at the 0.01 level (2-tailed).

*. Correlation is significant at the 0.05 level (2-tailed). 


\subsubsection{Regression}

Table 6 Regression

\begin{tabular}{|c|c|c|c|c|}
\hline Hypotheses & Beta & $\rho-$ value & Sig. & Remark \\
\hline TRL $\rightarrow$ JP & .489 & 0.001 & $<0.05$ & Accepted \\
\hline TFL $\rightarrow$ JP & .502 & 0.021 & $<0.05$ & Accepted \\
\hline
\end{tabular}

Note: . $\mathrm{R}=.703^{\mathrm{a}}$, $\mathrm{R}^{2}=0.612$. Std. Error of the Estimate. .511.

\subsection{Discussions}

H1: There is positive and significant impact Transformational Leadership on Nurses permeance at Temar medical Center.

Based on the result which has been generated in Table 5and 6, the relationship between the two variables is significant because the correlation is .826 and the regression $\mathrm{P}$ value 0.00 less than 0.05. thus, first hypothesis is accepted.

H2: There is positive and significant impact of Transactional leadership on Nurses permeance at Temar medical Center.

Based on the result which has been generated in Table 5 and 6, the relationship between the two variables is significant because the correlation is .763 and the regression P value 0.00 less than 0.05 . thus, second hypothesis is accepted. 


\section{CHAPTER FOUR}

\section{Conclusions and Recommendations}

\subsection{Conclusion}

The current study investigates the impact of leadership styles on the nurses' performance. the results indicated the both style of leadership (Transformational and Transactional) had positive and significant impact on nurses performance. However, the results indicated the Transformational more important than Transactional leadership based on nurses Perspective. This means the leaders should focus on the Transformational leadership style deal with nurses, respectfully talk to them about the future optimistically and prepare them to be leaders in the future. Meanwhile, Transactional leadership important as well, and the leaders should link the performance on the reward system and incentive. Here the leaders should distinguish between the nurses who prefer Transactional or Transformational style to deal with them based on preferable type. Thus, head nurses ensure the support, equity, and trust inspiration to the junior nurses so that the issue of nurses' performance can be increase to provide the quality healthcare service to the patients. Furthermore, nurse's managers must be aware about the effective leadership styles in their setting. Based on current study results transactional leadership style is least effective then the transformational leadership style.

\section{Recommendations}

1- The leaders in health sector should enhance the leadership style among their managers.

2- Managers should pay more attention on Transformational leadership style and enhance the trust and dignity in workplace.

3- Transactional leadership style should be exist as well in workplace and link the performance to reward system.

4- Performance of nurses able to enhance when the healthy environment exist, thus, leaders should improve this environment to increase the nurses productivity. 


\section{Reference:}

Amirul, S. R., \& Daud, H. N. (2012). A study on the relationship between leadership styles and leadership effectiveness in Malaysian GLCs. European journal of business and management, 4(8), 193-201.

Antonakis, J., Avolio, B. J., \& Sivasubramaniam, N. (2003). Context and leadership: An examination of the nine-factor full-range leadership theory using the Multifactor Leadership Questionnaire. The leadership quarterly, 14(3), 261-295.

Bass, B. M., \& Avolio, B. J. (1993). Transformational leadership and organizational culture. Public administration quarterly, 112-121.

Bass, B. M., \& Bass Bernard, M. (1985). Leadership and performance beyond expectations.

Bass, B. M., Avolio, B. J., \& Goodheim, L. (1987). Biography and the assessment of transformational leadership at the world-class level. Journal of management, 13(1), 7-19.

Bass, B. M., Waldman, D. A., Avolio, B. J., \& Bebb, M. (1987). Transformational leadership and the falling dominoes effect. Group \& Organization Studies, 12(1), 73-87.

Berggren, I., \& Severinsson, E. (2003). Nurse supervisors' actions in relation to their decisionmaking style and ethical approach to clinical supervision. Journal of Advanced Nursing, 41(6), 615-622.

Jameel, A. S., \& Ahmad, A. R. (2019, November). The effect of Transformational leadership on job satisfaction among academic staff. In The 34th International Business Information Management Association (IBIMA) Conference (pp. 13-14).

Bycio, P., Hackett, R.D., \& Allen, J.S. (1995), "Further assessments of Bass's (1985) conceptualization of transactional and transformational leadership", Journal of Applied Psychology,Vol. 80, pp. 468-478.

Fritzen, S. A. (2007). Can the design of community-driven development reduce the risk of elite capture? Evidence from Indonesia. World Development, 35(8), 1359-1375.

Hater, J. J., \& Bass, B. M. (1988). Superiors' evaluations and subordinates' perceptions of transformational and transactional leadership. Journal of Applied psychology, 73(4), 695.

Howell, J., \& Avolio, B. (1993). Transformational leadership, transactional leadership, locus of control, 
Jameel, A. S., \& Ahmad, A. R. (2020). The mediating role of job satisfaction between leadership style and performance of academic staff. International Journal of Psychosocial Rehabilitation, 24(04), 2399-2414.

Kahya, E. (2009). The effects of job performance on effectiveness. International Journal of Industrial Ergonomics, 39(1), 96-104.

Karem, M. A., Mahmood, Y. N., Jameel, A. S., \& Ahmad, A. R. (2019). The effect of job satisfaction and organizational commitment on nurses' performance. Journal of Humanities and Social Sciences Reviews. eISSN, 2395-6518.

Kirkman, B. L., Chen, G., Farh, J. L., Chen, Z. X., \& Lowe, K. B. (2009). Individual power distance orientation and follower reactions to transformational leaders: A cross-level, cross-cultural examination. Academy of management journal, 52(4), 744-764.

Ahmad, A. R., \& Jameel, A. S. (2020). Job satisfaction as a mediator between transformational leadership and organizational citizenship behaviours. International Journal of Advanced Science and Technology, 29(05), 10163-10174.

Küchler, S. (2008). Technological materiality: Beyond the dualist paradigm. Theory, Culture \& Society, 25(1), 101-120.

Jameel, A. S., \& Ahmad, A. R. (2019). Leadership and performance of academic staff in developing countries. In Proceedings of the 33rd International Business Information Management Association Conference, IBIMA (pp. 6101-6106).

Munyeka, W. (2014). The levels of motivation among employees in a selected public service department. Mediterranean Journal of Social Sciences, 5(20), 960-960.

Northouse, L. L. (2012, September). Helping patients and their family caregivers cope with cancer. In Oncology Nursing Forum (Vol. 39, No. 5, pp. 500-506). Oncology Nursing Society.

Northouse, L. L., Katapodi, M. C., Song, L., Zhang, L., \& Mood, D. W. (2010). Interventions with family caregivers of cancer patients: meta-analysis of randomized trials. CA: a cancer journal for clinicians, 60(5), 317-339.

Pounder, J. S. (2008). Transformational leadership: Practicing what we teach in the management classroom. Journal of Education for Business, 84(1), 2-6.

Schermerhorn Jr, J. R. (1975). Determinants of interorganizational cooperation. Academy of management Journal, 18(4), 846-856.

Smith, P. B., \& Peterson, M. F. (1988). Leadership, organizations and culture: An event management model. Sage Publications, Inc.

Yammarino, F. J., \& Bass, B. M. (1990). Transformational leadership and multiple levels of analysis. Human relations, 43(10), 975-995. 
Jameel, A. S., Ahmad, A. R., \& Abdul-Karem, M. (2020, July). Organizational Justice and Performance among academic staff. In Proceedings of the 35th International Business Information Management Association Conference, IBIMA.

Jameel, A. S. (2021). Job Satisfaction as a Mediator between Transformational Leadership and Organizational Citizenship Behaviours. 